Proceedings of the 2010 Winter Simulation Conference

B. Johansson, S. Jain, J. Montoya-Torres, J. Hugan, and E. Yücesan, eds.

\title{
LANDSCAPE FOR ANALYSING THE BUSINESS EFFECTS OF UTILIZING DESIGN SUPPORT SIMULATIONS
}

\author{
Johanna Mela \\ Product and Production Development \\ Tampere University of Technology \\ Tampere, 33720, FINLAND
}

Asko Riitahuhta

Product and Production Development

Tampere University of Technology

Tampere, 33720, FINLAND

\author{
Ricardo Velez Osuna \\ Visual Components Oy \\ Itsehallintokuja 6 \\ Espoo, 02600, FINLAND
}

Timo Lehtonen

Product and Production Development

Tampere University of Technology

Tampere, 33720, FINLAND

\begin{abstract}
Advanced design support solutions such as 3D simulations have enabled improved management of design information for years. The challenge, however, is that acquiring these type of design support solutions does not necessarily create a visible business value for the company in a short run. Moreover, the organization surrounding the simulation solution should support its use by providing the conditions and resources needed for utilizing it. Vice versa, design support solutions have to support the prevailing organizational conditions. Especially the interaction between the planned design-support solution, existing process structures and human related issues have to be understood to create the basis for business efficient design information management. Understanding the chain effects of employing different types of design support solutions has on organizational "ecosystem", creates basis for forming business-effective sustainable communication and design support structures. The Company Strategic Landscape introduced will form the framework for recognizing these chain effects in business environment.
\end{abstract}

\section{INTRODUCTION}

\subsection{Simulations as a tool for improving the information management and communication during the design process}

Design support simulation solutions provide a large scale of supporting operations for the design process. Research carried out by (Coze et al. 2009) shows that over 85 percent of product costs are incurred in the pre-manufacturing phase, product design being the single greatest expense. Another finding is that the main reasons for unsuccessful product design and manufacturing are the difficulties for manufacturing the product, components are not ready for production ramp-up and the lack of agility and time. Results strengthen the observation according to which companies should focus more on effective means to improve the design processes in order to overcome the repetitive problems in design and manufacturing. However, in many manufacturing companies the management requires evidence of the business value that can be created for the company by employing the design support solutions, such as simulations. This sets 
the challenges for the operational management to measure and make the potential of simulation solutions in creating business benefits for the company visible.

This paper divides simulations related to design process into three category: Concept development support-, product design \& process support-, and design verification support simulations. The main aim of the simulation solutions is the risk identification and elimination, action planning and problem solving during the design operations. Business benefits for the company can be gained with effectively implementing and utilizing simulation solutions to cut the design time, reduce errors in production and to improve the communication during the design process. One common example of the utilization of simulations in the product design are the 3D simulation based communication about the optional structural/component solutions in a product. With the visual representations of the optional solutions, problems in e.g. manufacturability can be detected in early design stage thus avoiding unnecessary remakes and problems in manufacturing. In the design verification simulations, the final design solutions and manufacturability are verified. 3D product model simulations are an effective way of communicating the product properties to different design parties, e.g. to suppliers or production, in early design stages. Product 3D modeling is traditionally achieved by integration of models created in different CAx-systems by different design teams. 3D simulation implementations are then tightly linked to CAx systems in use.

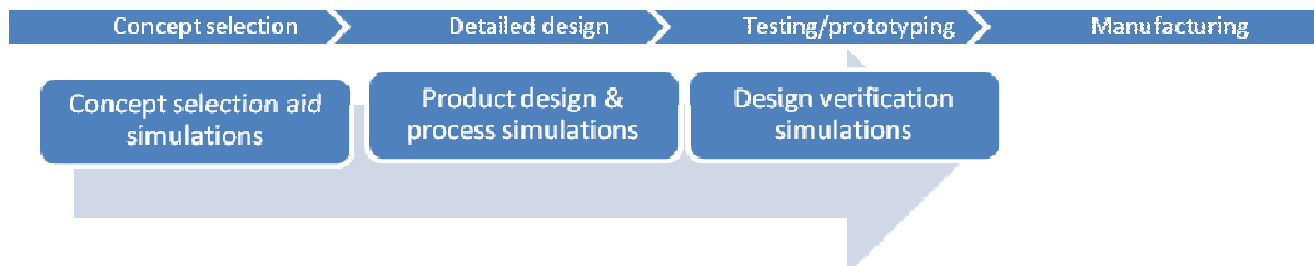

Figure 1: Classification of the design support simulations used in the paper.

Even though simulations are continuously improving their position as a support function for product design operations, rarely are the business effects of the use of these tools considered as a topic of discussion. Evaluating the impact the simulations may have for the business is a challenging field requiring organizational level understanding about not only the software tools or technical solutions, but the organizational aspects surrounding the use of the tools. In the end, it is the strategic goals of the company which should guide the selection and use of any tools and solutions in design or manufacturing operations. However, very often tools tend to be considered as an absolute value in themselves, without a realistic consideration about the possible value creation or cost effects they have during the design- or the entire product life-cycle. This is especially the case with the technologically evolved simulation techniques and methods where the technical implementation tends to steal the attention from the value creation perspective.

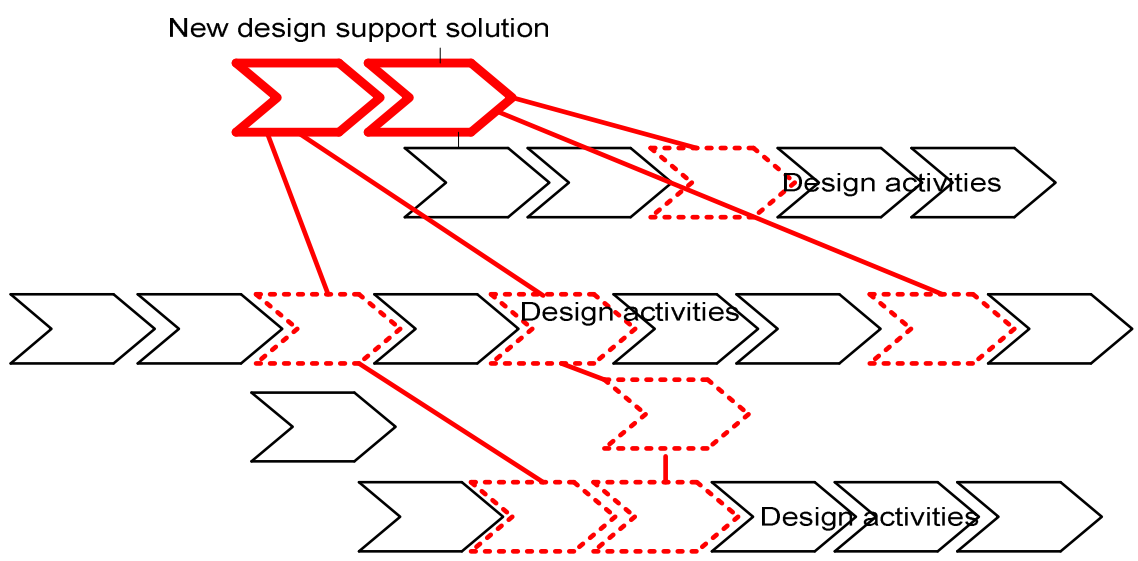

Figure 2: Take is Illustrating how employing a new design support solution in an organization can cause effects/chain effects in several design activities field. If these chain effects are not considered in the light 
of the organizational framework, the result of employing new solutions might end up causing unexpected and even dramatic business effects.

\subsection{Scope and content of the research}

The paper is defining the landscape for evaluating the business effects of employing new design support solutions in existing design process structures. The 3D simulations solutions field utilized as an aid for design and design communication is used as an example throughout the paper. Examining individual simulation tools is not the target of the study. As a classification of simulation solutions, the division of concept selection, product design process and design verification is used. The basis for viewing the effects of the use of simulations in design process and the organizational challenges in current industrial environments are viewed. The framework for the evaluation of the business effects of new design support solutions as part of the existing design process is introduced and the conclusions are drawn.

The knowledge behind the paper relies on years of experiences of the writers from working in the research, industrial management, management consulting and in simulation fields and for different company cases where simulation solutions have been utilized for improving the design and manufacturing operations, in some of them successfully and in others less successfully. Critical part of the research done during the co-operation with any of the organizations has been to create an understanding about the information landscape surrounding the product design environment. Implementation of product simulations in design requires data and information from different areas of the product organization and it is often the case that the relevant information and data for business effectively harnessing the new design support solutions in use is not easily available, at least not on time.

In the current work, design information is referred to as the kind of product related data, information or knowledge that can be recognized as remarkable for designing and manufacturing the product according to pre-set requirements. Theoretically, all the relevant design information could be "revealed" by unveiling the different processes included to product design.

\section{CASE DESIGN SUPPORT SIMULATIONS AS A TOOL FOR CREATING BUSINESS BENEFIT FOR THE ORGANIZATION}

\subsection{Need for defining the business value that can be gained by employing design support simulations}

It is possible to create financial benefits for the business by effectively utilizing simulations to support the design process activities. For instance, physical prototyping and product structure simulations can be replaced with virtual ones up to $100 \%$. Physical prototyping slows down the product development process, and can thus be a major bottleneck. It is also expensive and constraints the number of design alternatives that can be examined. Mere with cost of delay (COD) calculations can point out the substantial effects the simulations can have for the business. Physical prototyping can be even avoided when using effective simulation tools in design.

Experiments and learning can be carried out with simulations without disturbing the design scheduling or real manufacturing system. Alternative solutions can be compared within the system - constraints and possible problems can be identified before actions are taken in a real system. The realistic 3D models and animations can then be used for demonstrations and to train the workers (Nylund et al. 2009). By utilizing virtual product- and assembly simulation techniques, the designers can also model the assembly of a product before the actual product build and ramp-up at the factory, saving time and cutting costs from the design and manufacturing. However, prerequisite for improving these operations by utilizing simulations is the organizational ability to effectively manage, share and re-use product information during the design and manufacturing life-cycle.

Viewing the landscape for evaluating the business effects of the utilization of simulations in design is also obviously relevant from the manufacturing perspective. According to (Vos et al. 2001), assembly op- 
erations take more than $50 \%$ of the total production time and about $20 \%$ of the total unit production costs. Assembly is a labor-intensive sector and labor costs form a major part of the assembly costs. Thus assembly is often the weakest link in the whole production process. Assembly is also the production step closest to the customer needs. Changes in the customer demands have to be anticipated in the assembly process planning (Fowler and Rose 2004). Effective communication of manufacturing issues such as ability to assemble a certain design plan is a critical cost factor during the product process. By using product simulations in an early design stage, the assembly information of the design can be included to the design process in such way that they replace the time consuming and expensive product builds and remakes in the production. Substantial part of the benefits from utilizing simulations (in this case also) comes form the improved design communication mode.

In projects implemented with large design/manufacturing organizations by the authors during the past 5 years, several benefits from the simulations for the product processes have been recognized. Centralized product design data management and updates via 3D simulation system enabled gaining right information, to the right place, at the right time. Reduced the number of late design and manufacturing changes and reduced prototype builds and physical builds for manufacturability testing created substantial time reductions for the companies. Overall, the time from concept to prototype and number of prototypes was reduced which enabled faster time-to-market. Also, the assembly time was reduced by strengthening the company's ability to anticipate the challenges of production in early design stages. The analyses that can be implemented with simulations are e.g. time analysis, feasibility of assembly, ergonomic impact, and product reliability verifications. This leads to less parts, easier process steps, feasible assembly sequence, simpler tools, lower field failure rate, lower repair costs and eventually increased customer satisfaction. Information created during the design simulations could be utilized in production in user instructions and in training. These points out the relevance of simulation solutions as information management tools.

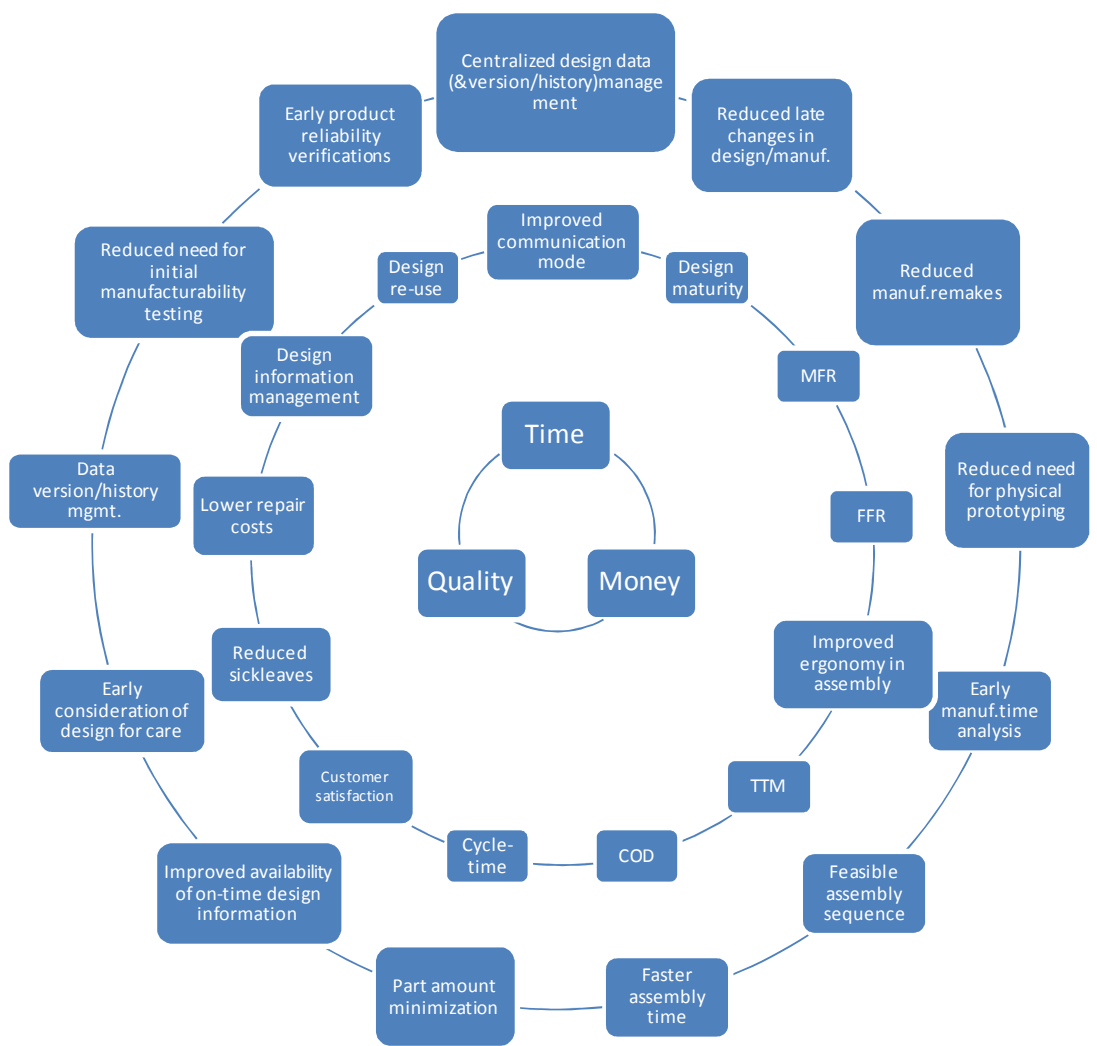

Figure 3: Representing some of the possible benefits of employing 3D simulations in design. Outer circle describes the effect, middle one examples of the indicators and the innermost the business effects. As in- 
dividual statements these improvement areas do no yet indicate the business benefit a new solution has to offer. When the chain effects from effect to value (time, money, quality) are revealed the evaluations of the business effects are enabled.

All of the issues recognized in the company cases can be identified to create benefits either in the form of time reductions, improved quality or decreased costs due to the first two. If employing design support simulations in the operations of the company can evidently be pointed to create value to the organization, it can be stated that the simulation solution has a business value. Value however, does not have to be shown in decreased design or production costs, but it can appear in other forms of valuecreation during the product life-cycle. Example of this type of value is e.g. increased market attractiveness of the product due the improved quality or faster time-to-market. This refers to better product information management in order to achieve better planning and control of design and manufacturing activities and more effective utilization of advanced design tools. (National Research Council 1998)

\subsection{Evaluating the business effectiveness of the design support simulations - creating visibility for the design activities}

Understanding the cause-effect chains leading to recognizable business benefits, such as time, money and quality, requires understanding about the ways in which design support simulations are connected to different design activities. Figure 4 and table 1 show an example of the effects of employing 3D simulations in design, leading to business effects potential for creating business benefits.

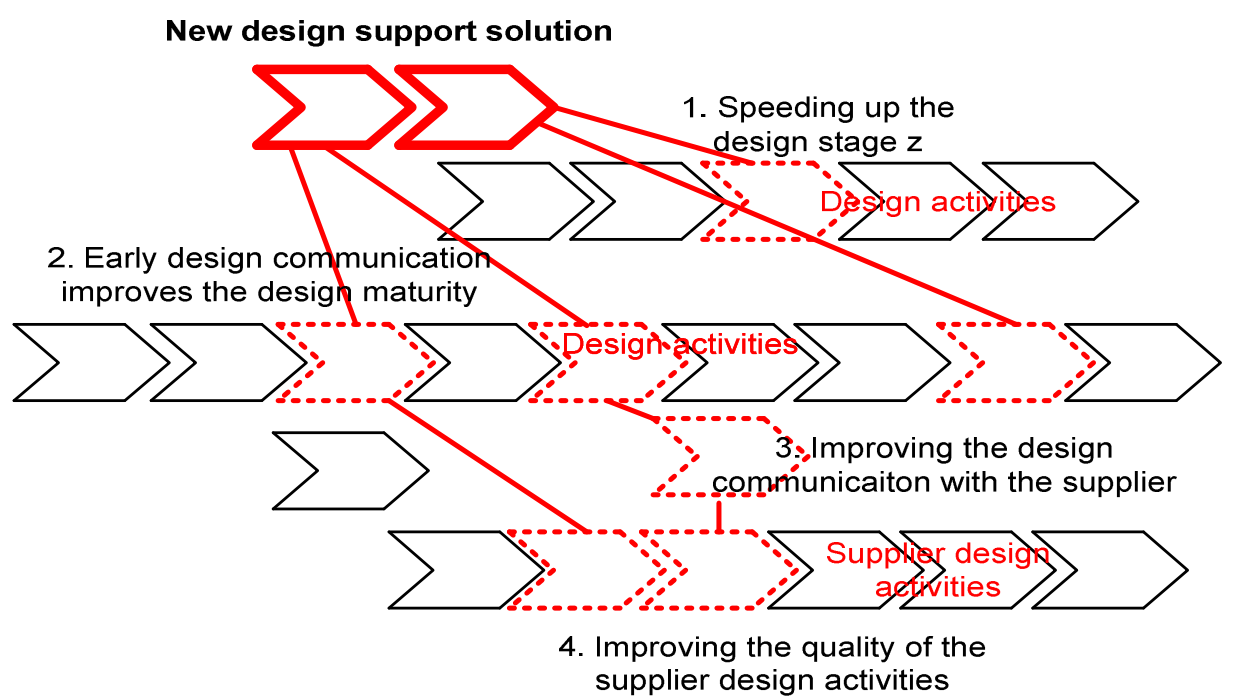

Figure 4: The benefits that can be gained by utilizing simulations in product design are often resulting from chain effects between the design activities. Figure shows examples of the effects the new design support solution can have for different design activities 
Table 1: Simple example of the effect chain factors of employing new design support system. Primary effect (1.-4-) caused by employing new design support solution as part of the design process should lead to measurable business effects which can be indicated in form of costs, time and quality.

\begin{tabular}{|l|l|l|l|}
\hline STARTING POINT & EFFECTS & CHAIN EFFECTS & BUSINESS EFFECTS \\
\hline $\begin{array}{l}\text { Simulations enable global on- } \\
\text { time design communication } \\
\text { mode }\end{array}$ & $\begin{array}{l}\text { 1. Speeding up the design stages z/k } \\
\text { faster design } \\
\text { time }\end{array}$ & COD, TTM, \\
$\begin{array}{l}\text { By utilizing simulations sev- } \\
\text { eral design stages can be } \\
\text { started/communicated earli- } \\
\text { er }\end{array}$ & $\begin{array}{l}\text { 2. Early design communication im- } \\
\text { proves the design maturity }\end{array}$ & $\begin{array}{l}\text { ramp/quality, } \\
\text { timanufacturing } \\
\text { quality/customer } \\
\text { satisfaction }\end{array}$ & $\begin{array}{l}\text { MFR, FFR, TTM, } \\
\text { COD cycle time }\end{array}$ \\
\hline $\begin{array}{l}\text { With 3D simulation based } \\
\text { design data sharing the sup- } \\
\text { plier can be included to } \\
\text { process earlier in a way that } \\
\text { supports information security }\end{array}$ & $\begin{array}{l}\text { 3. Improving the design communica- } \\
\text { tion with the supplier }\end{array}$ & $\begin{array}{l}\text { involvement, de- } \\
\text { sign maturity, } \\
\text { design time }\end{array}$ & MFR, TTM, COD \\
\hline $\begin{array}{l}\text { While suppliers have the } \\
\text { access for early design data } \\
\text { and the supporting systems, } \\
\text { the better design maturity is } \\
\text { enabled. }\end{array}$ & $\begin{array}{l}\text { 4. Improving the quality of the sup- } \\
\text { plier design activities }\end{array}$ & $\begin{array}{l}\text { improvements, } \\
\text { agility in the } \\
\text { competition }\end{array}$ & $\begin{array}{l}\text { value network } \\
\text { in value network/ } \\
\text { partnerships }\end{array}$ \\
\hline
\end{tabular}

\subsection{Current challenges in utilizing design support simulations business effectively - lack of visibility and fractured information and knowledge management practices}

Several benefits from utilizing the simulation techniques in design have been recognized. It is a case related matter though, whether this benefits can be translated into monetary- or otherwise measurable form. The challenge is that even though it can be stated overall, that simulations can create benefits in form of time, quality and costs, organizations lack the systematic evaluation processes to verify these benefits. One of the today's industrial paradigms is also that even though companies might have the latest technology and applications in their hands, they do not succeed in utilizing them in an effective manner. This makes the evaluations of the business effectiveness of the selected solutions very challenging. The main cause for this often relates to the lack of common practices for design/product information management, sharing and -reuse inside the product organization. The challenges appear especially in form of fractured information sharing practices inside the design/manufacturing organizations and the entire network. Problems also occur in overlapping non-centralized internal process structures and in process -based operation modes which limit the possibilities for practicing effective information management.

Besides of direct information management challenges, the implementation level problems in existing simulation solutions still occur. Although several commercially available simulation tools are available on the market, with wide range of capabilities, several barriers for wide adaptation still exist. The main barriers recognized by (IMTI 2003) includes inadequate simulation capabilities when fidelity of the simulation codes and the ability to simulate complex phenomena is often poor. Usability of simulation systems often requires substantial modifications and expert knowledge is needed to perform the simulations. Also lack of simulation synthesis - integrating multiple codes or designs into the simulation environment is usually impossible. High cost of developing tailored simulation capabilities plus psychological and sociological barriers against the acceptance of simulation tools have been recognized as a barrier for the wider acceptance of the product simulation systems. (Vos 2001)

As pointed in figure 5, the successful employment of design support simulations and information systems overall requires consideration of the people, processes and IT systems landscape. Often, especially in engineering based expert fields, IT solutions steals most of the attention and only little consideration is 
put on the fit of new IT solution into the social environment such as human attitudes and competences. Moreover, if the new solution is not viewed against the organizations' process structures, the rooting of new solution base for the existing organizational structures will be more expensive and time consuming.

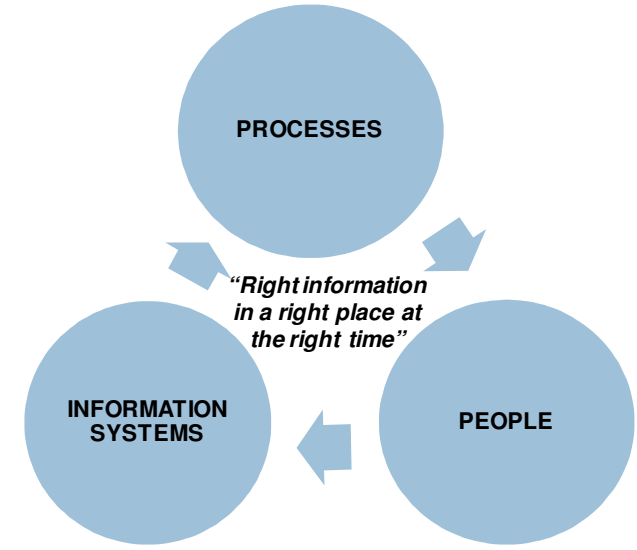

Figure 5: Current organizational practices for utilizing the simulations solutions in the design process often lack the underlying understanding about the interaction between processes, people and information systems. This leads to inadequate information management in which the rooting of new solution for the existing structures is challenging and the product information cannot be managed, shared or updated properly.

\subsection{Underlying information management challenges - a case example}

A good example of the challenges in design information management, for which figure 5 also refers to, was indicated in the research project launched in 2009 by Tampere University of Technology with several industrial companies. The conditions for capturing and managing critical product information were examined. The research viewed the organization- and process structures in the design production phases of the product life-cycle as well as the information systems in use for managing the critical information related to the design and production life-cycle of the product. The target was also to chart how the design information is really shared in the organization, especially between the design teams and production. The research was implemented partially inside the companies by interviewing people from R\&D and manufacturing representatives, charting the organization intranet and information systems in use and discussing with $R \& D$ and operational management. The current operational practices for managing and transforming the design information were mirrored against the organization strategy to create a deeper understanding of the correspondence between the strategies and operations. Figure 6 points out a common individual situation of the inadequate utilization of the simulation tools in the design process. The design data needed for forming and updating simulations is transformed from CAx systems through varying routes and the data management and updates are fractured.

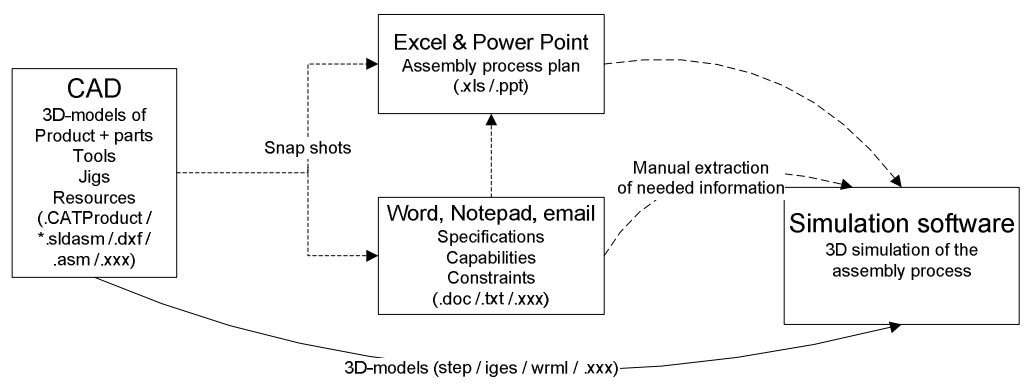

Figure 6: A case situation of the fractured product information sharing practices between CAx product modeling and simulation tools. (Järvenpää 2010) 
The lack of simulation synthesis often appeared as one of the biggest barriers for deploying simulations in product design in a business-effective manner. The lack of common use practices in using the information systems appear in many forms. In some cases the component manufacturers are using different CAx software which causes problems in creating matching formats for the simulation systems. If CAx data is transferred from one system to another (with e.g. STEP) unwanted filtering and other altering of data occurs. Interoperability issues between the CAx systems and simulation solutions may form an obstacle for an integrated simulation data management.

Several other examples of the challenges for effectively utilizing simulations in design exists. The common characteristic for most of the challenges however is that they usually relate to information and knowledge management issues which on the other hand cannot be completely understood without viewing the organizational landscape surrounding the problems. Moreover, the human related issues play a big part in understanding the source of the problems.

\section{LANDSCAPE FOR VIEWING THE CHAIN EFFECTS FOR EVALUATING THE BUSINESS EFFECTS OF EMPLOYING THE DESIGN SUPPORT SOLUTION}

When the business aspects of the utilization of design support solutions are considered, understanding the interaction of IT, processes and people is not enough. The underlying business landscape surrounding the organization specific design environment has to be understood. Figure 7 is called the Company Strategic Landscape (CSL). It describes the business viewpoint surrounding the product design and manufacturing processes. The business effectiveness of the utilization of simulation solutions in design can be evaluated by how it supports the strategic goals of the organization (figure7: CSL) and the existing process/human environment (figure 5: IT, processes, people). In the CSL landscape, employing the 3D simulations may have an effect on several fields. Mainly in the field of product- and process structuring, and especially as a tool for improving their interaction, but also in organizational structuring, e.g. in the area supplier communication.

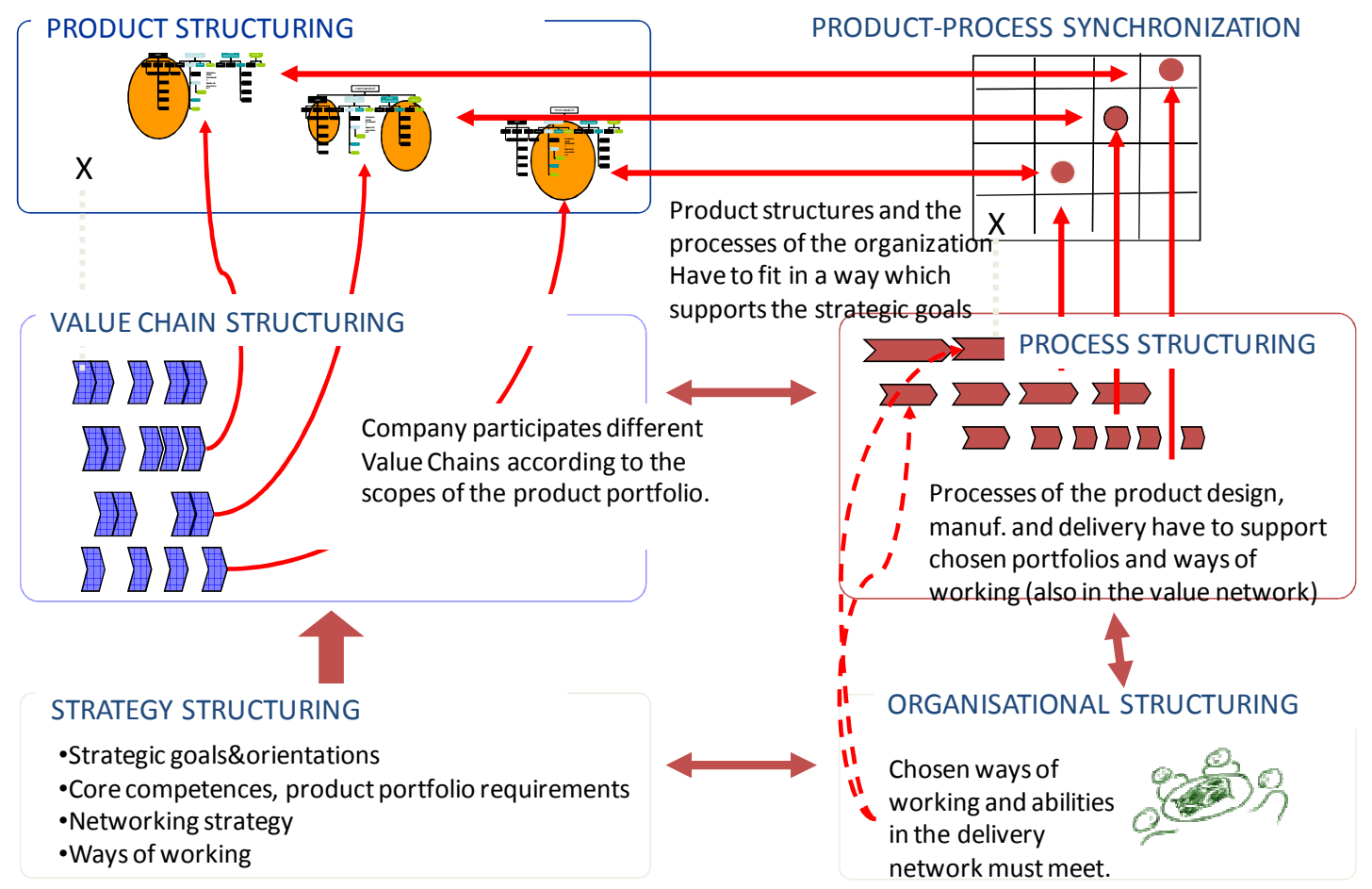

Figure 7: Company Strategic Landscape is illustrating the critical domains in a product design process. The business value of the design decisions can be viewed in the frames of the six domains represented in the picture, and their successful interactions. CSL is based on the work of (Lehtonen \& Juuti 2006). 


\subsection{Process and human related landscape}

Besides of the aspects represented in figure 7, the human related factors have to be viewed when the business-effective utilization of simulation solutions is considered. Internal processes of the organization mediate the product related information among different teams as well as between the different (as we call them) "hierarchical" levels of the organization. By this it is referred to the different administrative and operational human related structures that have to be considered when designing and manufacturing a product. During the years of co-operation with various especially large organizations, it has become apparent that in these "multiple matrix" -type of human related information structures, the design and product information is "flowing" through the different teams, units and design/manufacturing life-cycle phases but also through strategic, operational and e.g. marketing levels which all might include people from the same teams. The information flows can be divided in two classes, horizontal and vertical product information flows (see Figure 8). Certain "cornerstones" also can be recognized, mediating the critical information flows and appearing as a backbone (or a multi-dimensional network) carrying the core product and design information. These cornerstones can be e.g. process "milestones", "key action points" or individual employees of the organization.

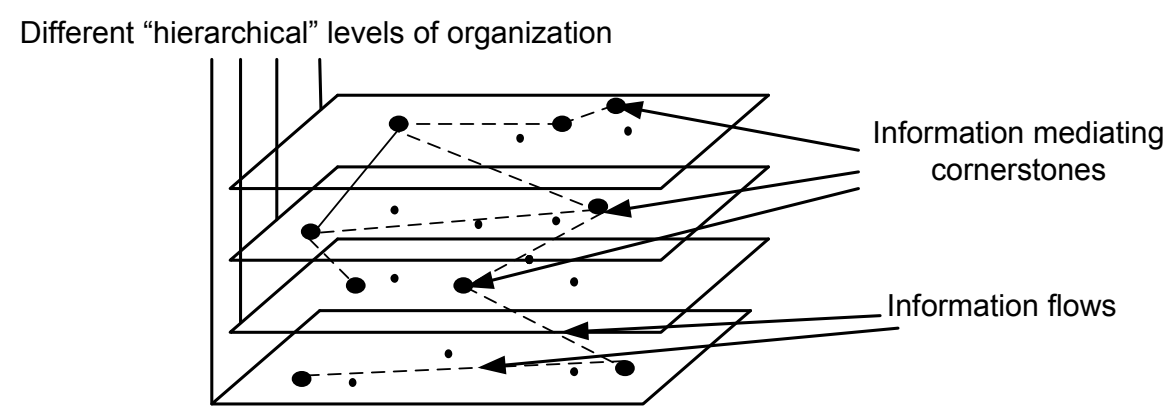

Figure 8: Illustration of how organization may contain several abstraction levels of product and design information. "Hierarchical" levels refer for instance to levels like corporate administration, marketing and operations which all can represent very separated information management entities in the organization information exchange culture. "Information mediating cornerstones" inside the same hierarchical level refer e.g. to different teams inside a marketing level through which the critical design/product information is flowing during the design process. This observation sets certain requirements for creating an understanding about of the product and design information structures. The information on the other hand is mediated by the organization processes flowing through the different teams and the hierarchical levels of the organization.

Though the strategic linings set by the organization management should guide the product and design information flows inside the organization, they do not necessarily set the guiding frame that would define the operational practices in design and manufacturing. This is typical phenomenon for the multiple matrix -type of organization structure.

\subsection{Evaluating the business effects of employing a design support solution - case: simulations for design}

Company Strategic Landscape can be used as the first framework for evaluating the fit of simulation solutions for the needs of a certain business. Traditionally, the fit of simulation solution is evaluated mainly from its technical implementation in design or manufacturing -perspective with a little consideration of what are the true business effects of the decisions. The person(s) responsible of acquiring the simulation 
tools usually represents merely a narrow perspective of the needs of the organization. Depending on the individual characteristics such as educational background, personal interests or the position in the organization, the person making the simulation tools and solutions acquisition might e.g. have tendencies to buy the cheapest or technically most advanced simulation solutions despite the true needs of the company. Figure 9 points out some of the most critical issues which have to be viewed when selecting the proper simulation solution for supporting the business needs of the organization. By viewing the business through CSL framework, different viewpoints for using the simulations in design can be culminated in form of questions that need to be answered.

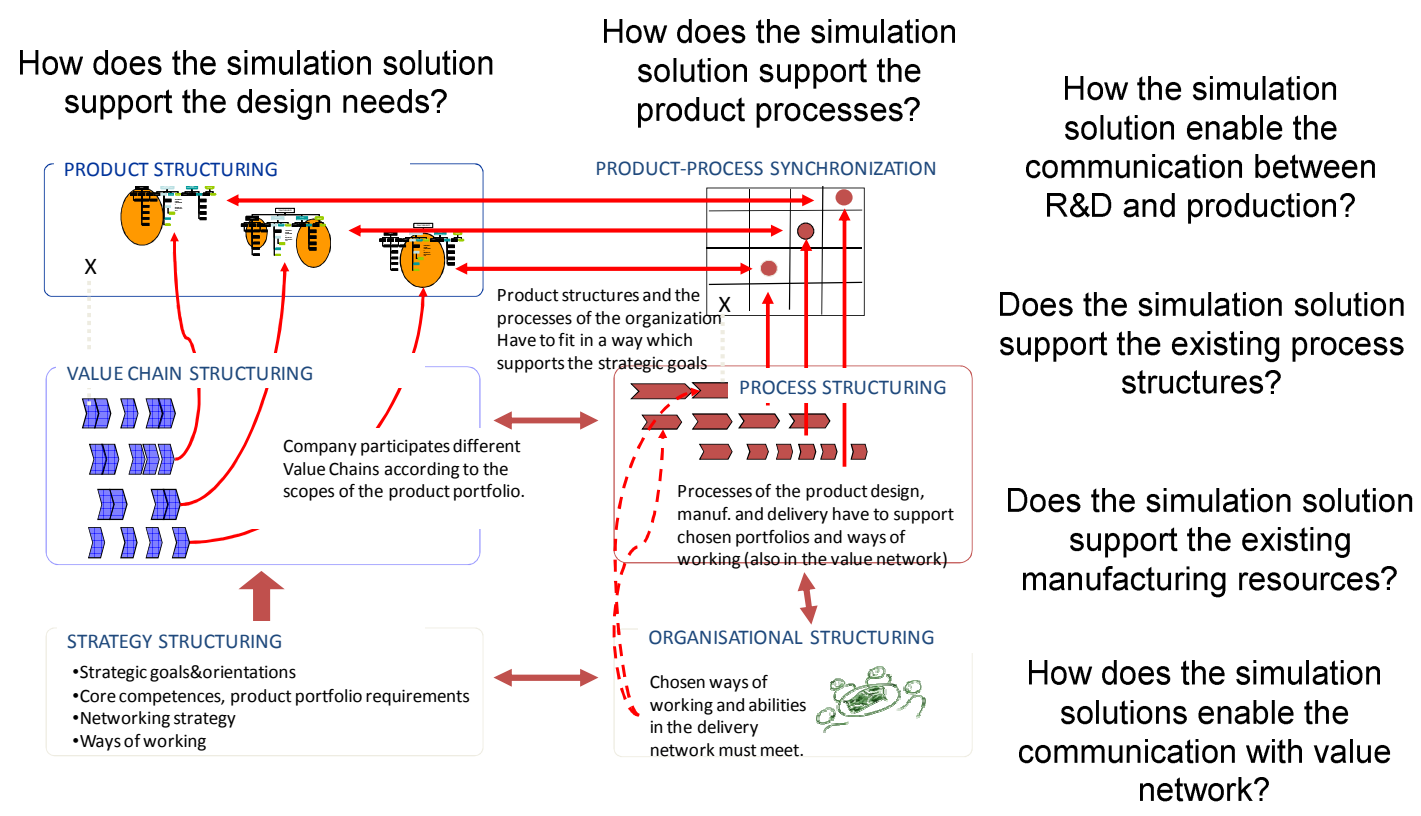

Figure 9: Some of the most critical decision support questions for selecting the right kind of simulation methods and tools for the business needs of the company. The CSL forms a landscape in which the fundamental questions related to the business potential of the new solution scenario can be structured. The questions are formed by viewing the needs of CSL domains and the needs that are formed by the communication requirements between the domains.

The human related issues, especially usability, acceptance and accessibility have to be considered when selecting the proper simulation solutions. Employees of the company are always the key factor for making successful business. The co-operation of the authors with several industrial fields has been pointing the lack of organization-wide common instructions for utilizing information systems often being the prevailing situation. Different teams of the companies are even in some cases using varying software for the common design information streams management. For instance, the personal preferences may lead certain employees to use Excel and email instead of the latest visual design support tools or product information management software integrated to company's intranet. Also, the responsibility sharing and roles inside the organization are often blurry. Obscurities occur of who should be responsible and/or perform the design support tasks, especially when it comes to managing the product data from different sources. Caused by this type of phenomenon, the full potential of the design support solutions is often not exploited.

In the end, all the questions presented in figure 9 have to be viewed through the interaction between people, processes and information systems of the company. This creates the basis for forming a deep understanding about the true design support needs of the organization hidden behind the needs of individual people representing their individual schemas and beliefs rather that the objective viewpoint targeting to improving the business. 


\section{WRAPUP}

It is stated that if employing a new design support solution in the existing operations can evidently create value to the organization, it then can be stated that the solution has a business value to the company. The business value can appear in different forms and an understanding of these forms should be created by viewing the business and operational landscape surrounding the planned solution. A framework for viewing the new design support solutions in business context then has to be created. Without the framework, organizations lack the competence and context for carrying out a systematic evaluation process in order to verify the benefits that can be gained by employing new solutions as part of the existing processes and human resource structures. Company Strategic Landscape was presented to indicate how the challenges arising from the business needs of the company lie behind the selection of the proper design support solutions for the need. CSL approach then serves as the first step for creating an understanding of the business needs behind the decisions. "Visionary manufacturing challenges" -report (National Research Council 1998) stated that the global trend is towards the state in which the information and knowledge, on all aspects of manufacturing enterprises and the marketplace, is instantly available in a form that can be effectively assimilated and used for decision making. The authors of this paper state that during the last ten years, it has been shown that advanced 3D simulation solutions represent one of the main tools of this trend. With the aid of simulations, the gateway for all product and design related information and for the global communication between different stakeholders of the product and design processes is enabled in a visual way which breaks the barriers of cultural and language areas. In figure 10, the true relationship of importance between the IT systems, processes and people is indicated based on the experiences when cooperating with tens of companies during the last ten years. In the end, no IT system saves us from poor management of processes and, first of all, people which are the most important factor for making any business successful.

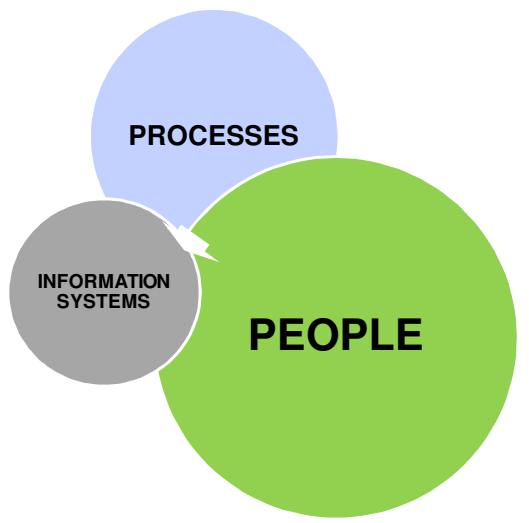

Figure 10: Based on the view created by the authors, the importance of human related factors is highlighted while it is stated that the value creation capacity of the IT solutions is fully dependent on the quality of its integration with process and human resources of the organization.

Increasing requirements for sustainable and dynamic design information management abilities in global competitive environment imply a new level of knowledge that is currently unavailable in many organizations. First of all, the transformation to new design information management mode requires a change of mindset towards more inclusive viewing of the organizational structures, even the ones not so visible for everyday operations or for the strategic decision making level. 


\section{REFERENCES}

Coze, Y., Kawski, N., Kulka, T., Sire, P., Sottocasa, P., and J. Bloem. 2009. Virtual Concept - Real Profit with digital manufacturing and simulation. Dassault systems and Sogeti. LINE UP book \& media. The Netherlands.

Fowler, J. W., and O. Rose. 2004. Grand Challenges in Modeling and Simulation of Complex Manufacturing Systems. Simulation, Vol. 80, No. 9, 2004, pp. 469-476.

IMTI Roadmap. 2003. Modeling and simulation for affordable manufacturing. Technology Roadmap Initiative, USA.

Järvenpää, E., 2010. Studying the information sources and flows in a company supporting the development of new intelligent systems. In Proceedings of the 2010 Flexible Automation and Intelligent Manufacturing International Conference, California, USA.

Lehtonen, T. 2006. Designing modular product architecture in the new product development. Doctoral thesis, Tampere University of Technology, Finland.

National Research Council. 1998. Visionary Manufacturing Challenges 2020. National Academy Press, Washington, USA.

Nylund, H., Salminen, K., and P.H. Andersson. 2009. An approach to the integrated design and development of manufacturing systems. In R. \& Shehab, E. (eds.), Proceedings of the 19th CIRP Design conference, Competitive Design, Cranfield University, UK Cranfield University Press. pp. 428-435

Vos, J.A.W.M. 2001. Module and System Design in Flexibly Automated Assembly. Ph.D. thesis. Delft University of Technology, Delft, The Netherlands. Delft: DUP Science. 198 p. ISBN 90-407-2195-5

\section{AUTHOR BIOGRAPHIES}

JOHANNA MELA is a Research Scientist at Tampere University of Technology, Finland. Her research includes product design methodologies and systems, IT infrastructures, simulation in design, human aspects in design, organizational structures. Her email address is $<j$ ohanna.mela@tut. $\mathrm{i}\rangle$.

RICARDO VELEZ OSUNA is Research and Development Manager for Visual Components Oy in Finland. He is in charge of all research and development initiatives for the company, which offers 3D simulation software for manufacturing and logistics to a wide range of manufacturing sectors. His research includes modeling and simulation of manufacturing systems, supply chain management, product design, 3D environments, intelligent systems, software development and user interfaces. His e-mail is <ricardo.velez@isualcomponents.com>

ASKO RIITAHUHTA is Professor of Product and Production Development at Tampere University of Technology, Finland. He has long and wide experience in product design methodologies and production methods. His e-mail is <asko.riitahuhta@tut.fi>

TIMO LEHTONEN is an Associate Professor at Tampere University of Technology and a partner at Nordic Element. He has long experience from design management projects in manufacturing industries and management consultancy in strategic design decision making. His e-mail is <timo.lehtonen@tut.fi> 